\title{
Fahotyp and sensitivity to medications phage film-forming strains Staphylococcus aureus, isolated from respiratory tract
}

\author{
Olga S. Voronkova ${ }^{1, a^{*}}$, Albert I. Vinnikov ${ }^{1, b}$ \\ ${ }^{1}$ Oles Honchar Dnipropetrovsk national university, Gagarin av., 72, Dnipropetrovsk, Ukraine \\ Email: ${ }^{a}$ email: voronkova_olga@inbox.ru, ${ }^{b}$ email: a_vinnikov@ukr.net
}

Keywords: staphylococci, biofilmformation, sensitivity to phages, bacteriophages drug.

\begin{abstract}
The study of biological properties of filmforming Staphylococcus aureus strains, including its sensitivity to bacteriophages, is one of the important tasks of laboratory diagnostic service that allows, if it necessary, choose an alternative treatment strategy and to establish the sources of strains. In the study of material from the nose and throat of 26 persons-volunteers the strains of $S$. aureus were selected. Among them 16 (61.5\%) were able to form biofilms. Analysis of resistance to phages drugs of filmformation strains of $S$. aureus showed that $87.5 \%$ strains were sensitive the phages drugs "Piobacteriophage" and "Bacteriophage staphylococcal liquid". Phage type was identified for $9(56.3 \%)$ strains. $64.3 \%$ of these strains were sensitive to the 1 phage from set, $21.4 \%$ - to 2 and $14.3 \%$ - 3 phages. It was determined that $77.8 \%$ strains were typed by phages from third group. For 1 strain detected simultaneous sensitivity to phages of 2 and 3 groups. With phage 81 (out of group phage) interacted 4 strains: 2 showed sensitivity only to him and another 2 were also susceptible to phage of third group.
\end{abstract}

\section{INTRODUCTION}

Microbiota of the human body is one of the different protective factors of body, so the support of their normal composition is important for human health. The microbiota may include opportunistic bacteria and carrier of them is widespread. This microorganisms been in microbiota as commensals form, but can cause pathological processes, especially in persons with weakened immune systems function [1,2,3]. Specific peculiarity of numerous opportunistic microorganisms is their ability to form biofilms. This is special status of microorganisms being, characterized by resistance to influence of environmental factors, including antibiotic. In the biofilm cells form clusters, surrounded by an external matrix, which is saturated by channels for transport of water, oxygen and nutrients. Periodically, some cells moves off and giving rise to a new cluster [4]. Biofilm is characterized as a basic form in which associations of microorganisms are in natural biocenoses.

One of the most well-known opportunistic pathogens, that are widespread among people, are staphylococci. Usually latest colonize the nasal cavity. The frequency of nasal carriage ranges from 20 to $40 \%$ and sometimes to $80 \%$. Epidemiological studies show that $20 \%$ of the population are resident carriers of staphylococci, $70 \%$ - are transient carriers, and only in $10 \%$ persons staphylococci not always detected [2,4]. One of distinctive peculiarities of staphylococci is their ability to form biofilms. As part of this structure they become more resistant to antibiotics. The increase of resistance is significant, sometimes more than 500 times compared to cultures that doesn't form biofilms $[4,5,6]$, so antibiotics become ineffective. Due to this there is a need to find additional ways to treat infections caused by film-forming strains $[7,8]$. One of potential additional agents are the bacteriophages, which make a specific effect on bacteria without harming of normal microorganisms [5,7].

Besides that considerable practical interest has the phage typing of staphylococci, that can help to solve the problem of finding of the source of staphylococci spreading [9].

The aim of research was to identify of phage type and sensitivity to bacteriophages drugs of film-forming Staphylococcus aureus, isolated from the upper respiratory tract of volunteers. 


\section{MATERIALS AND METHODS}

Biological materials from the upper respiratory tract (samples of nose and pharynx mucus) of 26 volunteers were studied. Identification of selected strains based on signs listed in Bergey's manual of determinative bacteriology [10] with use of API Staph kit (bioMerieux).

Samples of biological materials were inoculated on the saline meat-peptonic agar (contents of $\mathrm{NaCl} 10 \%$ ). Inoculated plates incubated at temperature $+37{ }^{\circ} \mathrm{C}$ for $18-24$ hours. Next step was microscopy of materials from colonies. Materials from all colonies, contained gram-positive cocci, analyzed on ability to use glucose and mannitol as one source of carbon in anaerobic condition with formation of acid or acid and gas respectively; production of plasmocoagulase $[11,12,13]$. If this test were positive for following identification procedure used Api Staph-Ident Systeme.

The ability to biofilmformation determined for pure culture of selected strains were seeded in the wells of plate in an amount not less than $10^{5} \mathrm{CFU} / \mathrm{ml}$. The plates were incubated at temperature $+37^{\circ} \mathrm{C}$ for 3 days. If this period formed biofilm - bottom or surface growth in the wells that gave the film, settled on the walls when culture medium was removing, the strain considered as filmforming. For each strain 3 wells of plate were seeded. Results recognized as positive if at least in one of the three wells formation of biofilm took place within 72 hours.

The sensitivity to bacteriophages drugs determined with "Piobakteriophage polyvalent" (Sextaphage) and "Bacteriophage staphylococcal liquid" (Microgen). In experiments 3-6-hour broth culture of studied strains were seeded by "lawn". Plates were divided into 2 sectors, on each a 1 drop of phage was applied on the surface. Plates incubated at temperature $+37{ }^{\circ} \mathrm{C}$ for $18-24$ hours. The positive reaction characterized as complete absence of growth of the culture in the drop square (active bacteriophage) or appearance in this place small sterile plaques (bacteriophage weak activity) [14].

For phage typed use international standard set for phage typing. For experiments was used method of drops.

\section{RESULTS AND DISCUSSION}

By the results of study of morphological, tinctorial, culture, physiological and biochemical characteristics of strains as $S$. aureus were identified 26 strains isolated from the upper respiratory tract (mucus of nose and pharynx). Able to form biofilm in the laboratory conditions had 16 $(61.5 \%)$ strains, that agrees with the known data [4].

Using of phage drugs have an interest in case of resistance to antibiotics. These drugs have the specificity of action against some bacterial pathogens even strains level and at the same time are safe for human and saprophyte microflora. Besides that bacteria can't acquire resistance to them [15].

We made a study of the sensitivity of the isolated film-forming strains to certain bacteriophages drugs.

In experiments was found that majority of the selected strains of $S$. aureus had sensitivity to phages of both studied drugs - Piobakteriophage and Bacteriophage staphylococcal liquid. Some strains showed sensitivity to both drugs, while others only one of the two.

Among film-forming strains susceptible to phages of medications "Piobakteriophage" and "Bacteriophage staphylococcal liquid" were 87.5\%. 12 strains were sensitive to both drugs simultaneously. Another 4 strains were sensitive to one of two drugs: 2 for each.

Character of lysis varied for phage with different drugs. Total lysis was observed for $50 \%$ of strains, but in other cases on the phages drops square a growth of single colonies were seen.

The lack of $100 \%$ sensitivity effect is a typical phenomenon for phage therapy, because receptors on the bacterial cell surface and phage receptors is variative structures. Using monovalent phage, usually the effect doesn't reach $15 \%$ for strains, isolated from different sources. That's why nowadays the using "phage cocktails", that include different bacteriophages, is recommended [5]. This mixed system allow to achieve more effective action with the use of phages. At the same time 
phages are not widespread medications, because they have high specificity to the host cell. Thus, the virus is able to destroy only the cells of sensitive strains, and no other cells. In this sense, an antibiotic with broad spectrum of action have significant advantages over bacteriophages: they destroy all bacteria that have specific target, including the pathogen [7]. For these reasons, the use of "phage cocktails" can resolve the issue of a narrow spectrum of viruses of bacteria and make the efficiency of phage preparations to antibiotics. Also phages are effective against biofilms, including an antibioticresistant microorganisms, that gives phages an additional advantages over antibiotics [16].

For phage typing used International set for phage typing of staphylococci. In the studies found that to applied phage sensitivity had $9(56.3 \%)$ isolated strains of $S$. aureus, able to biofilmformation. The rest 7 (43.7\%) were not sensitive to used phages.

The analysis of sensitivity to phages of isolated strains showed their affiliation to different type (Fig. 1). The $25 \%$ of the 16 strains were typed by phage 47 and $81 ; 18.8 \%$ - by phage 53 ; $12.5 \%$ were sensitive to phage 75 and $6.3 \%$ - to phage 55 .

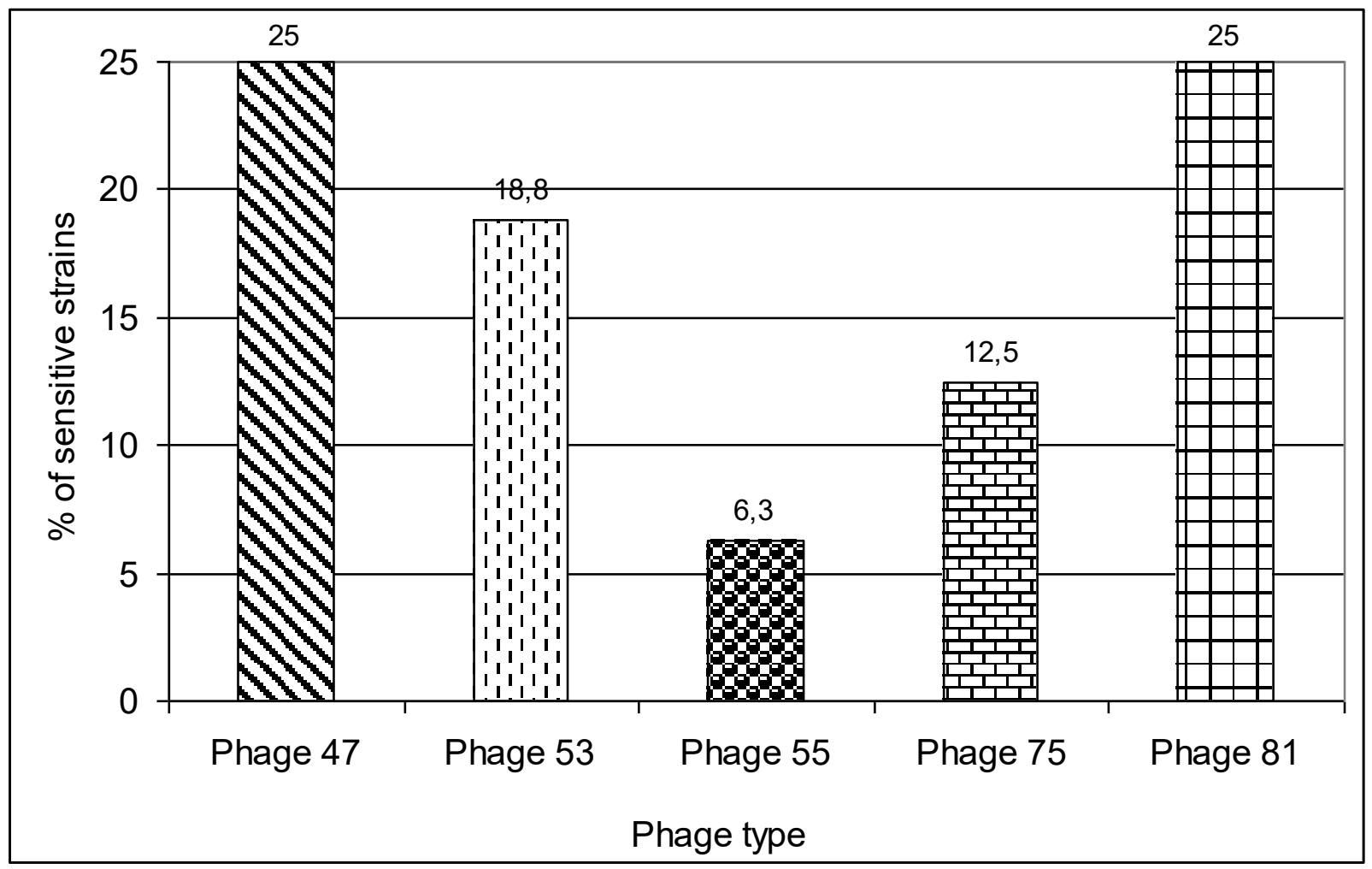

Fig. 1 Frequency detection sensitivity typical film-forming phage strains of staphylococci

From 9 strains with positive reaction, $64.3 \%$ were sensitive to 1 of the phages, for 2 and 3 phages $21.4 \%$ and $14.3 \%$ of strains were sensitive respectively.

So found that the majority of strains were typed by phage from third group: 7 of 9 strains $(77.8 \%)$ typed at least 1 of the phages from this group. For 1 strain detected simultaneous sensitivity to phages 53 and 55 (the latter belonging to the second group of phage from the set). With phage 81 (out of group phage) interacted 4 strains, two of which showed sensitivity only to it.

For a number of data $[17,18]$ the phage profile and possibility of phage typing of cultures may differ depending on source of their isolation. Thus, claimed on that the differences in peculiarities of staphylococci strains, isolated from the skin of healthy people and those with dermatitis took place [18]. The difference in the percentage of strains that may be typed is not great, while phage profile is much larger. Similar trends are described for staphylococci strains isolated from the vagina of healthy women [17].

It is known that on the basis of specificity distinguish different phages: polyvalent bacteriophages, lysed culture of one family or genus of bacteria; monovalent (monophages), lysed 
culture of only one species of bacteria, and typical bacteriophages, that have the highest specificity and can cause lysis only certain types (variants) of bacterial culture within the bacteria species. From this point of view, analysis of received data about specificity of studied strains, can clearly sorted the strains to certain phage type. This may indicate the possible existence of differences in the structure of the cell wall, composed of cytoplasmic membrane, receptors, etc., that in turn can be the key to the study of the formation of biofilms. In the latter process the bacterial cell surface structures play an important role. So determination of phage type can be one of the probable tests for the study of process of biofilmformation.

\section{CONCLUSION}

A. It was determined that the ability to form biofilms had $16(61.5 \%)$ strains of $S$. aureus, isolated from the upper respiratory tract of 26 volunteers.

B. It is established that the $87.5 \%$ of studied strains were sensitive to phages of drugs "Piobakteriophage" and "Bacteriophage staphylococcal liquid".

C. Sensitivity to phages from International set for phage typing of staphylococci was found for 9 $(56.3 \%)$ strains of $S$. aureus, able to biofilmformation. To one of the phages from set $64.3 \%$ of strains were sensitive, to two or three phages $21.4 \%$ and $14.3 \%$ of strains were sensitive respectively.

D. It was determined that majority of strains typed by phage of third group: $7(77.8 \%)$. For one strain detected simultaneous sensitivity to phages of second and third groups. With phage 81 (out of group phage) 4 strains interacted: 2 of them showed sensitivity only to it and other 2 were also susceptible to phage of third group.

\section{Gratitude}

The authors are grateful V.E. Kudryavtseva - Head of the Laboratory of Microbiology and Immunology of "Institute of gastroenterology of the National academy of medical sciences of Ukraine" (c. Dnipropetrovsk, Ukraine) for enabling a series of experiments in the laboratory.

\section{References}

[1] T.D. Savchuk, Staphylococcal infections, Medicine, Moscow, 2003.

[2] J. Klem, D. Dömötör, G.Schneider, T. Kovács, A. Tóth, G. Rákhely, Bacteriophage therapy against Staphylococci, Acta Microbiol. Immunol. Hungarica. 60(4) (2013) 411-422.

[3] A.K. Seth, M.R. Geringer, K.T. Nguyen, S.P. Agnew, Z. Dumanian, R.D. Galiano, K.P. Leung, T.A. Mustoe, S.J.Hong, Bacteriophage therapy for staphylococcus aureus biofilm-infected wounds: a new approach to chronic wound care, Plast. Reconstr. Surg. 131(2) (2013) 225-234.

[4] N.K. Archer, M.J. Mazaitis, W. Costerton, J.G. Leid, M.E. Powers, M.E. Shirtliff, Staphylococcus aureus biofilms: properties, regulation and roles in human disease, Virulence. 2(5) (2011) 445-459.

[5] B.K. Chan, S.T. Abedon, C. Loc-Carrillo, Phage cocktails and the future of phage therapy, Future Microbiol. 8(6) (2013) 769-783.

[6] C. Potera, Phage renaissance: new hope against antibiotic resistance, Envir. Health Perspect. 121(2) (2013) a48-a53.

[7] A. Sulakvelidze, Z. Alavidze, G. Morris jr., Bacteriophage therapy, Antimicrob. Agents Chemother. 45(3) (2001) 649-659. 
[8] J. Ziemska, A. Rajnisz, J. Solecka, New perspectives on antibacterial drug research, Cent. Eur. J. Biol. 8(10) (2013) 943-957.

[9] R. Pantucek, J. Doskar, V. Ruzickova, P. Kasparek, E. Oracova, V. Kvardova, S. Rosypal, Identification of bacteriophage types and their carriage in Staphylococcus aureus, Arch. Virol. 149 (2004) 1689-1703.

[10] J.G. Holt, N.R. Krieg, P.H.A. Sneath, J.T. Staley, S.T. Williams (Eds.), Bergey's manual of determinative bacteriology, Williams \& Wilkins, Baltimore, 1994.

[11] I.I. Volkov, Improving the microbiological diagnosis of staphylococcal infections and environmental aspects of their pathogens, 1999. Information on http://nature.web.ru/db/msg.html?mid=1163020.

[12] About the unification of microbiological (bacteriological) research methods used in clinical diagnostic laboratories of medical institutions: the order № 535, MOZ USSR, Moscow, 1985.

[13] M.K. Roberts, The diagnosis of staphylococcal infection, Mir, Moscow, 2005.

[14] S.H. Dzahurov, F.F. Rezepov (Eds.), Handbook of bacterial and viral preparations application, Medicine, Moscow, 1995.

[15] D.H. Lloyd, Alternatives to conventional antimicrobial drugs: a review of future prospects, Vet. Dermatol. 23(4) (2012) 299-304.

[16] Z. Hosseinidoust, N. Tufenkji, T.G.M. van de Ven, Formation of biofilms under phage predation: consid erations concerning a biofilm increase, Biofouling. 29(4) (2013) 457-468.

[17] D.Z. Ekmuzheva, S.B. Khadzegova, Characteristic of the normal vaginal microflora in healthy women of reproductive age, Uspekhi sovremennogo estestvoznaniya. 6 (2003) 50-51.

[18] O.E. Falova, N.I. Potaturkina-Nesterova, E.N. Ilina, Interrelation of intraspecific variety and genetic determinants of skin's staphylococcus pathogenicity, Fundamental research. 12 (2013) $131-134$. 